\title{
Spatial and Temporal Analysis of Urban Sprawl and Air Quality Index: a Review of Environmental and Anthropogenic Determinism of Microclimate Change in Indian Cities
}

\author{
Mintu Jana ${ }^{1}$, Taniya Roy ${ }^{2}$ \\ ${ }^{1}$ State Aided College Teacher (SACT), Department of Geography (UG\&PG), Bajkul Milani Mahavidyalay (VU), West Bengal, India \\ janamintu6@gmail.com \\ ${ }^{2}$ State Aided College Teacher (SACT), Department of Geography (UG\&PG), Bajkul Milani Mahavidyalaya (VU), West Bengal, India \\ taniya.roy0801@gmail.com
}

\begin{abstract}
Urban expansion and microclimatic modification both are correlated with each other. Urban expansion is changing the urban microclimate and destroys the standard air components in the urban region. Urban Air pollutants are day to day increase due to rapid population explosion in these selected cities. The objective of this paper is to provide insight details about the increasing rate of different air pollutants in different cities in India. Assess the spatiotemporal changes in air pollutants at different times in various cities. Comparison between Environmental Determinism and Anthropogenic Determinism for Urban microclimate modification. The National Air Quality Index (NAQI) ensures comparison amongst various cites of various air pollutants with different times. In this paper, I assess the Landsat 8 (libra.developmentseed.org) data also using the important reference coordinate systems, like Universal Transverse Mercator (UTM), World Geodetic System 1984 (WGS84) North Zone 45. I used the originally 2014 and 2018 satellite images, which urban growth image created by the use of three bands (B2 - Blue, B5 - Near Infrared, B7 - Shortwave Infrared 2).This series satellite image is used to show only the urban density analysis of various cities. A significant correlation between urban expansion due to population explosion in selected cities based on geospatial analysis and Air pollutants level dynamic change with the different time.
\end{abstract}

Keywords: Air Quality Monitoring, Radiometric Resolution, Population Density, Environmental Determinism, Anthropogenic Determinism

\section{Introduction}

Urban microclimate studies are popular day today due to rapid urbanization. Because due to the rapidly increasing population and highly influencing of the urban climate in the world. In the 21 st-century world population rapidly increase by the census United Nations (UN) and the World Bank. This percentage change is expected to occur due to the increase in the number of cities, migration from rural to urban areas, and transformation of some rural settlements into urban areas. UN sustainable Goals are recently making a rule "Cities and human settlements climate-resilient and sustainable". "Urbanism as a way of life" a book is describing how much facility is achieved by the urban dwellers. Louis writh said the urban as a facility provider industry to the Urban dwellers. Microclimate refers to "the ambient physical condition due to either atmospheric variables or exchanges with other bodies over some time representative of all the condition determined by the natural and manmade forcing factors" (Camuffo, 1998). Atmospheric variables, such as temperature, precipitation, and sensible and latent heat fluxes are important for human society. Meanwhile, these variables are sensitive to anthropogenic activities that modify land surface properties and land-atmosphere connections (Hartg et al., 1997;
McMichael et al., 2006). Urban air quality is one of the most prominent environmental concerns for modern city residents and authorities. Accurate monitoring of air quality is difficult due to intrinsic urban landscape heterogeneity and the superposition of multiple polluting sources. Pollution has become a great topic of debate at all levels and especially air pollution because of the enhanced anthropogenic activities such as burning fossil fuels, i.e. natural gas, coal, and oil to power industrial processes and motor vehicles. The burning of these fossil fuels releases a different harmful chemical to the atmosphere, like carbon dioxide (CO2), carbon monoxide (CO), nitrogen oxide (NOx), Sulphur dioxide (SO2), and tiny solid particles-including lead from gasoline additives-called particulates. An increase in industrial activities, population both endemic and floating, and vehicular population, etc. have led to a rapid increase in environmental problems like Air-population. India's urban population is expected to go up from 377 million in 2011 to about 600 million for the year 2031. This implies an increase of over 200 million in just 20 years. About $60 \%$ of the growth in the urban population in the past is due to natural increase whereas rural urban migration has contributed to only about $20 \%$. There is a concentration of urban population in large cities and existing urban agglomeration. The census of 2011 states that 53 million-plus cities are accounting for $43 \%$ of India's urban population. The census 
of 2011 also notes that the number of towns in India increased from 5161 in 2001 to as many as 7935 in 2011. Most of this increase was in the growth of census towns rather than on statutory towns. A large number of towns are born in the vicinity of existing cities with a million-plus population. India's urbanization, however, is in a smaller proportion as compared to other large developing countries such as China (45\%), Indonesia (44\%), Mexico (78\%), and Brazil (87\%). (Source - 12th Five-year plan - Planning commission of India). There are 53 urban agglomerations in India with a population of 1 million or more as of 2011 against 35 in 2001. Each such outgrowth may not satisfy the minimum population limit to qualify it to be treated as an independent urban unit but may deserve to be clubbed with the principal town as part of an urban spread. However, the definition of metropolitan areas adopted by the Planners in several cities, however, much larger areas including villages, whether urbanizing or 34 otherwise, but which are at the periphery or intervening in an urban agglomeration.

Under National Air Monitoring Programme three criteria pollutants (NAMP) viz. PM10 (Particulate Matter having an aerodynamic diameter less than or equal to $10 \mu \mathrm{m}$ ), Sulphur dioxide (SO2), and Nitrogen dioxide (NO2) were identified for regular monitoring at all locations. Additional parameters like Carbon monoxide (CO), Ammonia (NH3), Lead $(\mathrm{Pb})$, and Ozone $(\mathrm{O} 3)$ are being monitored at selected locations. The other parameters as notified in revised NAAQS (National Ambient Air Quality Standards) viz. PM2.5 (Particulate Matter having an aerodynamic diameter less than or equal to $2.5 \mu \mathrm{m}$ ), benzo (a) pyrene (BaP), arsenic (As), and nickel (Ni) are slowly being added under the monitoring network. The monitoring of meteorological parameters such as wind speed, wind direction, relative humidity, and temperature have also been integrated with air quality monitoring. The air quality index is used to assess the overall environmental condition and its trends with a specific standard. It is based on the lines of health index and measured by the degree. In the present work, an attempt has been made to evaluate the concentration of ambient air pollution like PM10, PM2.5, SO2, NO2, CO, And Ozone for some years. Following the selected months within a specific day by the perspective on sun inclination angle on different cities. Another explains the urban expansion how its impact on microclimate in these urban areas.

\section{Literature Review}

\section{Indian National Ambient Air Quality Standard}

Standard air quality is better of health condition and healthy environment in this Earth atmosphere. Central Pollution control board (CPCB) are decided standards scale of air pollutants are notified Indian National Ambient Air Quality standards for 8 parameters.

\section{Air Quality Index (AQI)}

Atmospheric risk assessment measure by the Air Quality Assessment (AQI). This is an important procedure for judgment any urban microclimate analysis and identification of the harmful pollutant for the children, the elderly, and those with existing cardiovascular and respiratory diseases.AQI is represented as a numeric value that varies from 0 to 500 . If the score is 0 , it is the best air quality and if the score is 500, it is the worst air quality (Higher AQI higher pollution). Air Quality Index (AQI) categories are namely Good, Satisfactory, Moderate, Poor, Very Poor, and Severe. Every category is decided based on the ambient concentration of air pollutants and their health impacts. Here Air Quality sub-index and health breakpoints are depending on eight pollutants. Eight pollutants are PM2.5, PM10, NO2, $\mathrm{SO} 2, \mathrm{CO}, \mathrm{O} 3, \mathrm{NH} 3$, and $\mathrm{Pb}$ for which short-term (up to 24hours) National Ambient Air Quality Standards are prescribed. The worst sub-index determines the overall AQI.

\section{Air Quality Monitoring}

In India, CPCB implements the National Ambient Air Quality Monitoring (NAMP) through a network comprising 544 operating ambient air quality stations covering 224 cities /towns in 26 states and 5 Union Territories of the country in compliance with the mandate under the Air (prevention and control pollution) Act, 1981 to collect compile and disseminate the information on ambient air quality.

\begin{tabular}{|c|c|c|c|c|c|c|c|c|c|c|}
\hline Pollutant & $\mathrm{PM}_{10}$ & $\mathrm{PM}_{2.5}$ & $\mathrm{NO}_{2}$ & $\mathrm{NH}_{3}$ & $\mathrm{SO}_{2}$ & $\mathrm{CO}\left(\mathrm{mg} / \mathrm{m}^{3}\right)$ & \multicolumn{2}{|c|}{$\mathrm{O}_{3}$} & $\mathrm{~Pb}$ \\
\hline Averaging Time (hr) & 24 & 24 & 24 & 24 & 24 & 1 & 8 & 1 & 8 & 24 \\
\hline Standard & 100 & 60 & 80 & 400 & 80 & 4 & 2 & 180 & 100 & 1 \\
\hline Note: Here all units are in $\mu \mathrm{g} / \mathrm{m}^{3}$ unless mentioned otherwise \\
\hline Source: Central Pollution Control Board (CPCB) \\
\hline
\end{tabular}

\section{Statement of the problem}

These selected cities are mainly based on the same population and different altitudes. Because every urban microclimate is highly affected by the urban population explosion. These selected cities are the highly changing scenario of their Atmospheric pollutants due to the urban expansion. Every city is a major role play in the state and nation. These cities either character state capital or regional capital in these regions. We found that day to day cities population increase and decrease the urban healthy environment. Here twelve cities are selected different latitude and longitude and achieved the different climatic conditions. All cities are different microclimatic characteristics carry in India. Because all cities' absolute locations and altitudes are so different. This work is one type of analytical research and argument the cities absolute location and their altitude how much prevents the microclimatic change due to injury by the Anthropogenic activity. The selected cities' population is rapidly increasing day to day due to Immigrants. Those are coming from the rural area due to lack of jobs opportunity and wellness facilities in these villages. After independence and policy of centralization migrants are always push by the fragmented village economy. Now India's urban regions are suffering from urban air pollutants, traffic congestion, poor drainage facility, homelessness, poor road network, poor solid waste 
management, job opportunity, and well planning for a better environment provide to all urban dwellers.

\section{Selection of the Study Area}

We have selected the twelve cities only bases their different space characteristics and their population scenario. All selected cities are located different region in India. Different their microclimate, altitude, temperature and moisture characteristics. Another important criterion follows their environmental sensitivity such as precipitation, strong wind and their cultural practices. These twelve cities are nearly about same population growth rate carrying but different their Air Quality Index (AQI) level in their microclimate. All criterions takes for the better judgement the urban air quality controlling factors, such as environmental determinism and anthropological determinism which is most build-up for selected urban climate. We are also assessing the different AQI, different urban growth rate, and their different population status. A suitable example discussing for better understanding their air pollutants determinants thought of various cities in India.

\section{Location of the Study area}

Our study areas are twelve different cities located different state in India. Geographically all selected urban region is geographically more diversity carrying in India. First of one, these twelve cities include the six categories only them near about population status and urban growth rate. Because a dualism discusses between environmental determinism and anthropological determinism, which is more powerful for urban air quality build-up in India.

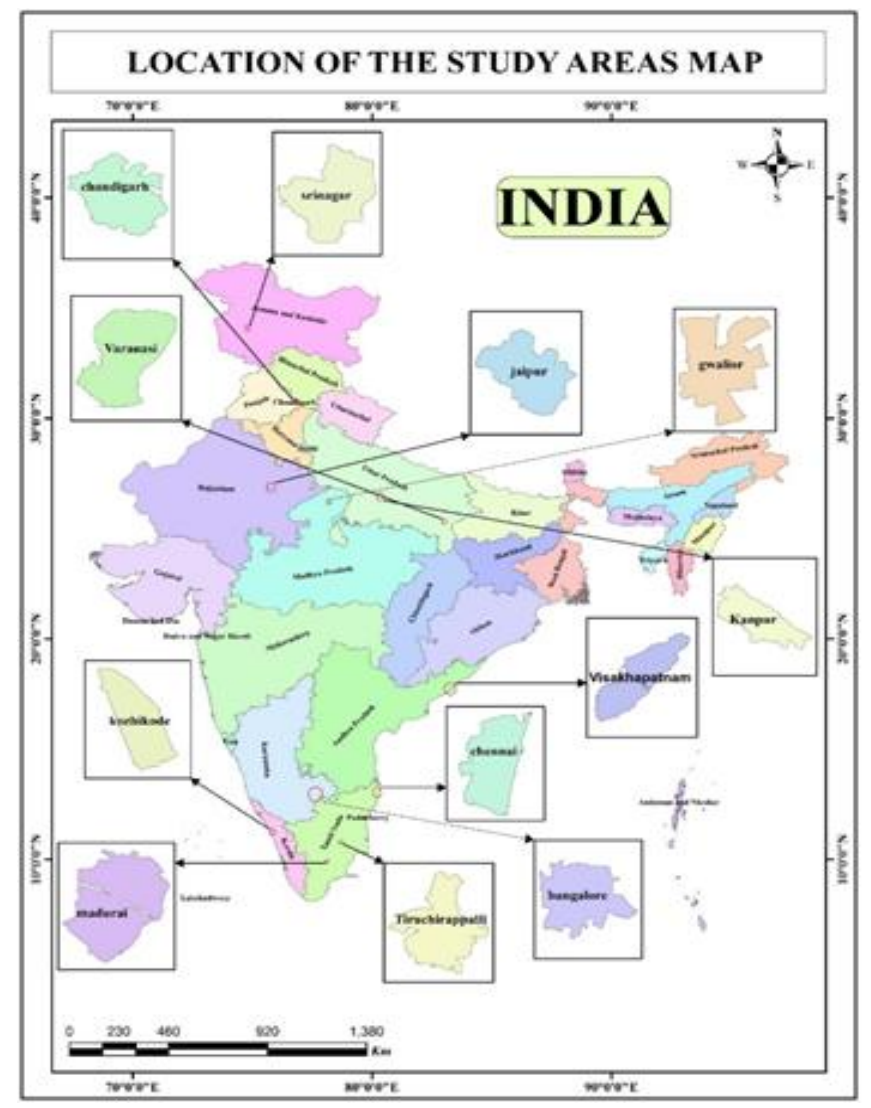

\section{Objectives \& Hypothesis}

The main objective of this work -

1) To identify the changing scenario of Urban population and residential density within various cities.

2) To examine the changing scenario of Air pollutant components in these cities during some year's interval.

3) Determine which are major role-play of Environmental Deterministic approach and Anthropogenic Deterministic approach for modified microclimate within different cities.

4) To assess the Air Quality Index (AQI) of selected cities in India.

5) To identify how absolute location and altitude are prevented from changing manmade urban microclimatic modification within the same populous cities.

\section{Methods \& Methodology}

The study has been conducted based on only secondary data, which has been collected from the concerned department and download from the authorized website. To see the urban map, I analysis of Landsat 8 (libra.developmentseed.org) data also using important reference coordinate systems, like Universal Transverse Mercator (UTM), World Geodetic System 1984 (WGS84) North Zone 45.

Here I used the originally 2014 and 2018 satellite images, which urban growth image created by the use of three bands (B2 - Blue, B5 - Near Infrared, B7 - Shortwave Infrared 2), and all satellite maps were collected from libra.developmentseed.org. All satellite image is collected 5 January, 10 January, and 18 January. The temporal variation of all satellite images is 4 years. All air pollutants are collected from National Air Quality Index. These are official online open sources link build-up by Central Pollution Control Board (CPCB) in India. I have selected the four months mainly June, March, September, and December based on Sun Inclination Angle on Northern Hemisphere in the Earth.

The methodology to calculate the air quality index (AQI) is presented below, along with the supporting data for various ranges.

$\mathrm{AQI}=\frac{\mathrm{AQI}_{\mathrm{hi}}-\mathrm{AQI}_{\mathrm{lo}}}{\mathrm{BP}_{\mathrm{hi}}-\mathrm{BP}_{\mathrm{lo}}} *\left(\mathrm{CONC}-\mathrm{BP}_{\mathrm{lo}}\right)+\mathrm{AQI_{ \textrm {lo } }}$

Where,

CONC $=$ Concentration of the Air Pollutant

$\mathrm{AQI}=$ Air Quality Index for the Air pollutant

$\mathrm{BP}_{\mathrm{hi}}=$ the breakpoint that is greater than or equal to CONC

$\mathrm{BP}_{\mathrm{lo}}=$ the breakpoint that is less than or equal to CONC

$\mathrm{AQI}_{\mathrm{hi}}=$ the $\mathrm{AQI}$ value corresponding to $\mathrm{BP}_{\mathrm{hi}}$

$\mathrm{AQI}_{\mathrm{lo}}=$ the $\mathrm{AQI}$ value corresponding to $\mathrm{BP}_{\mathrm{lo}}$

All graphs are created by the MS EXCEL for their percentage wise distribution. Arc GIS 10.5 version are Important GIS software for assess the different satellite image analysis of selected cities. 
Table 1: Different tools and techniques for Completed Paper work

\begin{tabular}{|c|c|c|c|}
\hline Different stage & & Applicable Methods & Tools \& Techniques \\
\hline \multirow{5}{*}{$\begin{array}{c}\text { First stage } \\
\text { (Selection the topics } \\
\text { and research area) }\end{array}$} & & Study Area Selection & \multirow{2}{*}{ In depth thinking on this selected topic } \\
\hline & \multicolumn{2}{|r|}{ Statement of the Problem } & \\
\hline & \multicolumn{2}{|r|}{ Literature Review } & Online Literat \\
\hline & \multicolumn{2}{|r|}{ Research Design Making } & \multirow{2}{*}{ Only the based-on statement of the problem } \\
\hline & \multicolumn{2}{|r|}{ Objectives Formulation } & \\
\hline $\begin{array}{l}\text { Second stage } \\
\text { (Search the topic wise } \\
\text { data sources) }\end{array}$ & $\begin{array}{c}\text { Data } \\
\text { Collection }\end{array}$ & Secondary & $\begin{array}{l}\text { Landsat } 8 \text { series satellite image, National Air Quality index, } \\
\text { Sequential records of population and AQI, Books, Reports, } \\
\text { Articles, Journals, Documents from various sources }\end{array}$ \\
\hline \multirow{6}{*}{$\begin{array}{c}\text { Third stage } \\
\text { (Processing \& } \\
\text { Implementation Phase) }\end{array}$} & \multirow{2}{*}{\begin{tabular}{c|} 
Data \\
Processing \\
\& Analysis
\end{tabular}} & Data Organization & \multirow[b]{2}{*}{$\begin{array}{l}\text { Application of Different formulas MS Excel, SPSS software, } \\
\text { etc. }\end{array}$} \\
\hline & & \begin{tabular}{|c|} 
Data Compilation \\
Data Calculation \& Present
\end{tabular} & \\
\hline & \multicolumn{2}{|c|}{ Urban growth Mapping analysis } & ARC GIS \& ERDAS IMAGINE \\
\hline & \multicolumn{2}{|c|}{ Result \& Discussion } & Based on Collected Data, Its Analysis \& Mapping Analysis \\
\hline & \multicolumn{2}{|r|}{ Hypothesis Justification } & $\begin{array}{l}\text { Result Justification comparing with Previously formulated } \\
\text { Hypothesis \& Final Decision and Recommendations Providing }\end{array}$ \\
\hline & \multicolumn{2}{|r|}{ Final Report Writing } & All assessment result studying and final report writing \\
\hline
\end{tabular}

\section{Sequential air pollutants materials level monitoring of selected cities}

All air pollutants materials are dynamically change within all urban area in India. We have been starting sequential data collection from 2014 and end of data collecting year 2019. Four months selected in each year for this paper pollutants data collection. Because these four months are selected on the basis of sun position. Because all seasonal change in the earth surface due to sun position and sun inclination angle with the earth surface. The national Air quality Index (NAQI) is a regulatory body by Indian government standard measure of air pollutants comparison between various urban area. We have seen that seven air pollutants parameter are collecting from $\mathrm{CPCB}$, and graphically represent this statistical analysis data for better understanding air quality level of selected cities in India. All air pollutants material status of selected cities in given bellow:

\section{a) Particulate Matter 10:}

We have found that suspended solid particles are important determinants for air quality. Here Bangalore and Varanasi urban area in their air $\mathrm{PM}_{10}$ are more found than the others urban area. But Vishakhapatnam, Jaipur and Chennai are lowest $\mathrm{PM}_{10}$ carrying than the other two cities.

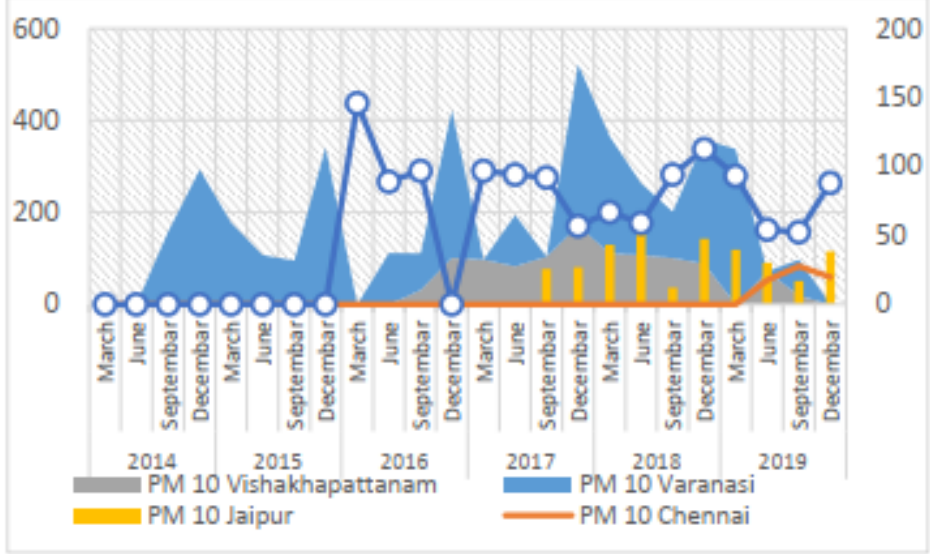

\section{b) Particulate Matter 2.5:}

Particulate maters released from non-combustible materials such as fly ash, and atmospheric reactions of sulphur oxides and nitrogen oxides. Here another pollutants $\mathrm{PM}_{2.5}$ are very high ratio carrying Kanpur, Varanasi, Vishakhapatnam and
Chennai urban area because these urban areas are known to industrial metropolitan cities. 


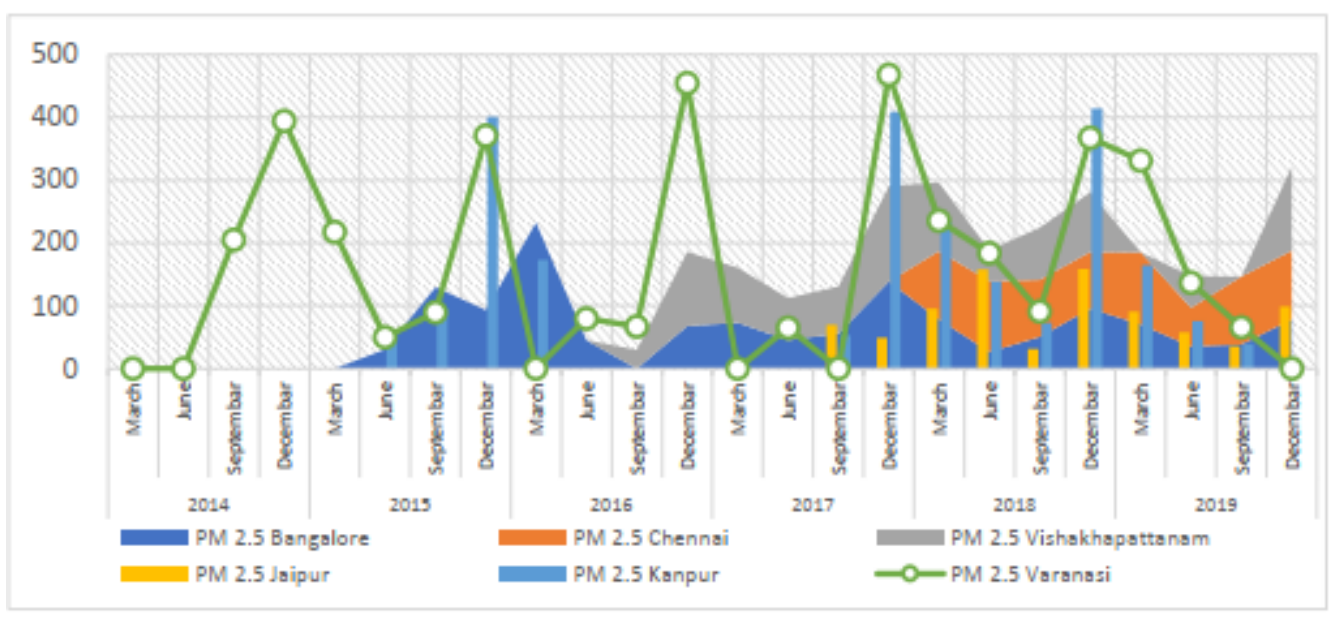

\section{c) Nitrogen Dioxide $\left(\mathrm{NO}_{2}\right)$ :}

Nitrogen Dioxide $\left(\mathrm{NO}_{2}\right)$ are main source from the combustion of fossil fuels (Coal, gas and oil) especially fuel used in cars. Here Varanasi, Kanpur and Jaipur all interior urban area are most $\mathrm{NO}_{2}$ carrying than the other selected cities, because these urban areas are achieved the less environmental sensitivity. But Chennai, Vishakhapatnam are known to industrial cities but these two cities are known to coastal cities.

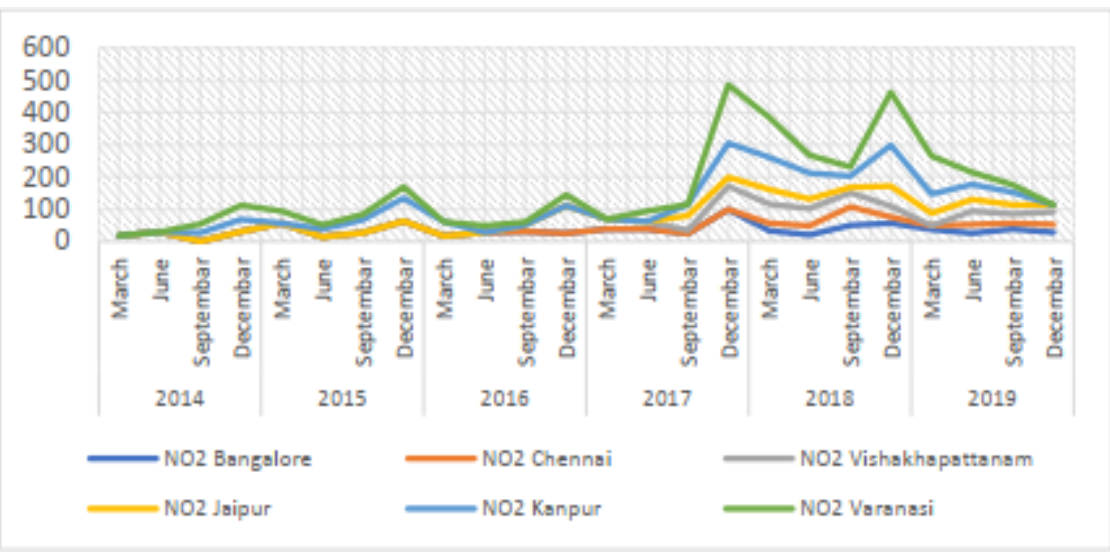

d) Ammonia ( $\left.\mathrm{NH}_{3}\right)$ :

Ammonia (NH3) is a toxic gas which is the attack the human eyes and respiratory system. Ammonia reacts quickly with other air pollutants to form ammonium sulphate and ammonium nitrate, contributing to the overall particulate matter burden. Ammonia (NH3) released from fertilizer industry and its application. We have found that Varanasi, Vishakhapatnam and Chennai are more ammonia present in their atmosphere.

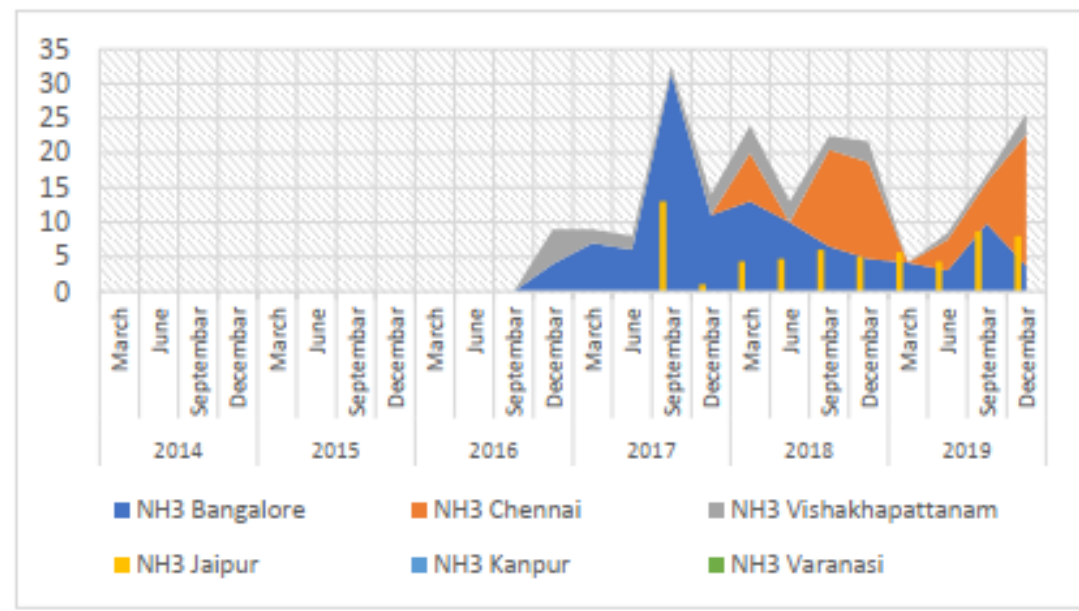

e) Sulphur Dioxide $\left(\mathrm{So}_{2}\right)$ :

Sulphur dioxide (SO2) are emitted by the burning of fossil fuels- coal, oil and diesel- or other materials that contain sulphur. We have found that Varanasi and Kanpur carrying the most sulphur dioxide (SO2) than the other cities. 


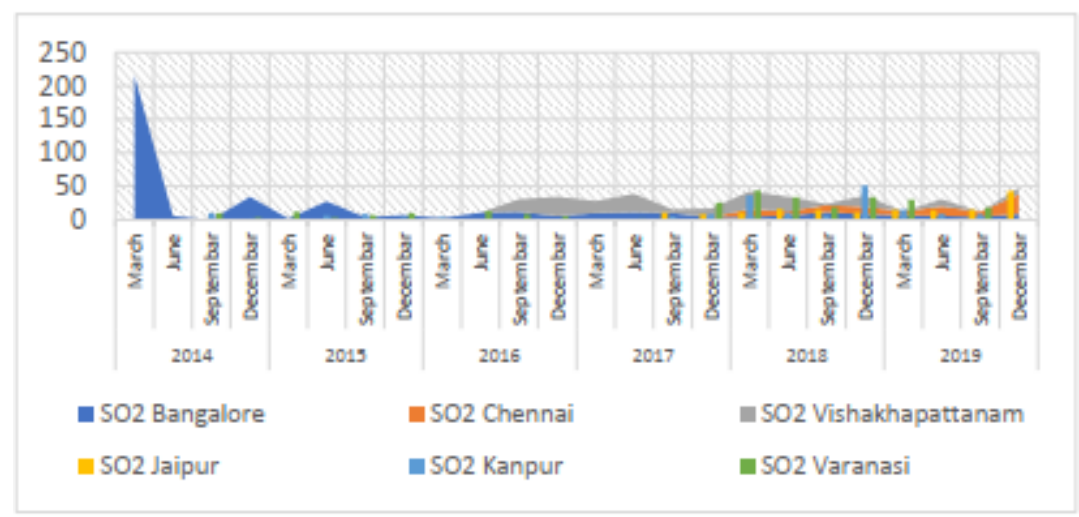

\section{f) Carbon monoxide (CO):}

Carbon monoxide $(\mathrm{Co})$ is released from the combustion of carbon containing fuels, such as gasoline, natural gas, oil, coal and wood in urban area in India. Here we have found that Varanasi and Kanpur are microclimate carbon monoxide $(\mathrm{Co})$ more present in their atmosphere.

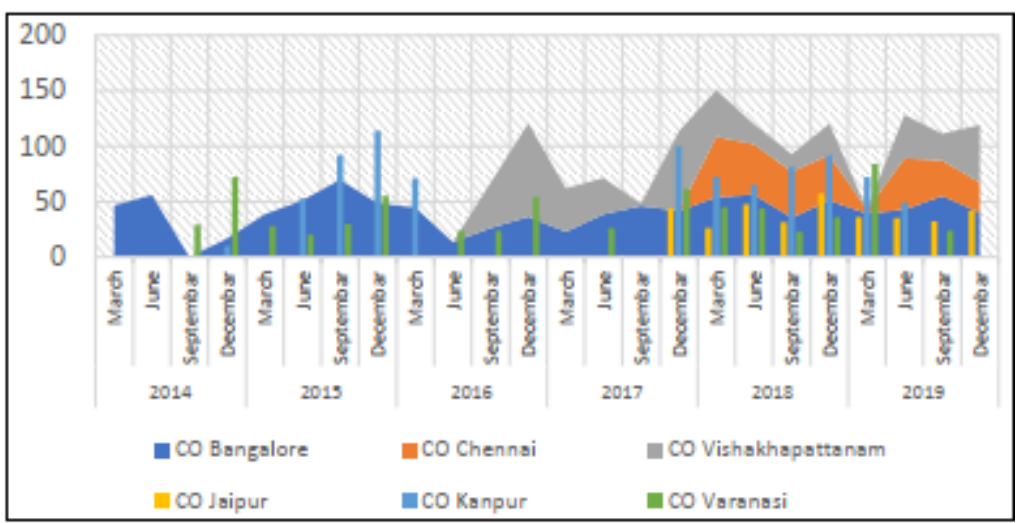

g) Ozone $\left(\mathrm{O}_{3}\right)$ :

Ozone depleting important substances includes; Chlorofluorocarbons (CFCs), hydrochlorofluorocarbons (HCFCs), hydrobromoflurocarbons (HBFCs), halons, methyl bromide, carbon tetrachloride, methyl chloroform all are released from human residential elements. We have found that Bangalore, Chennai and Vishakhapatnam are less carrying the Ozone gasses in their microclimate, but other cities are huge carrying the Ozone gases.

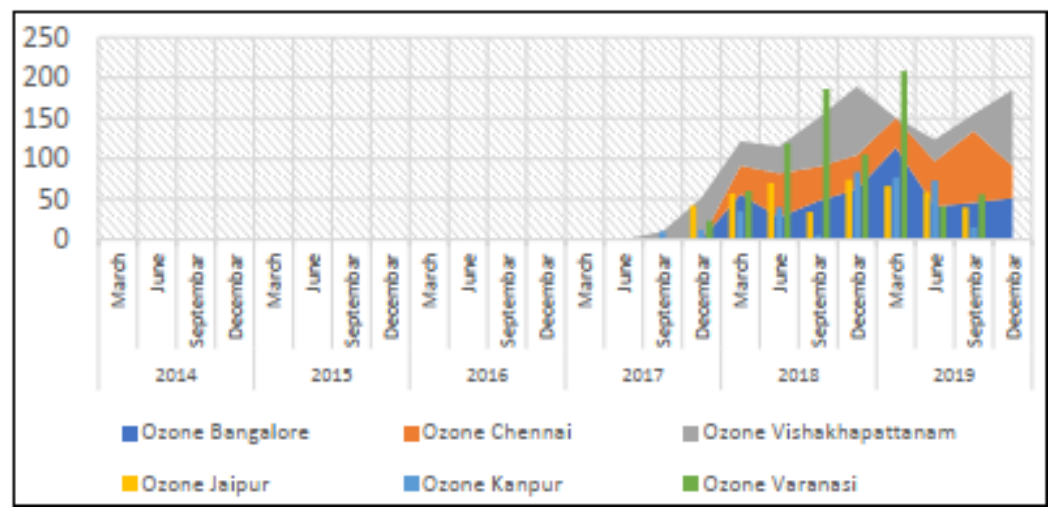

\section{h) Air Quality Index of selected Cities:}

All atmospheric air pollutants are built up the air quality index through the National Air Quality Index (NAQI) monitoring station proposed by Central Pollution Control Board (CPCB). Here we some cities are missing their AQI data by the no build air quality monitoring station within the cities. We have found that Air quality index are dynamically increases some cities and some cities have decreases their air quality index data. Such as Varanasi, Kanpur,
Vishakhapatnam and Chennai cities air quality index are sequentially increasing. But Kanpur and Varanasi cities air quality index are more than the other cities. Here coastal cities are carrying less air pollutants in their air quality index, but other cities are carrying more air quality index. Because microclimatic hazardous and sensitivity are more active in coastal and plateau cities than the plain land interior cities in India. 


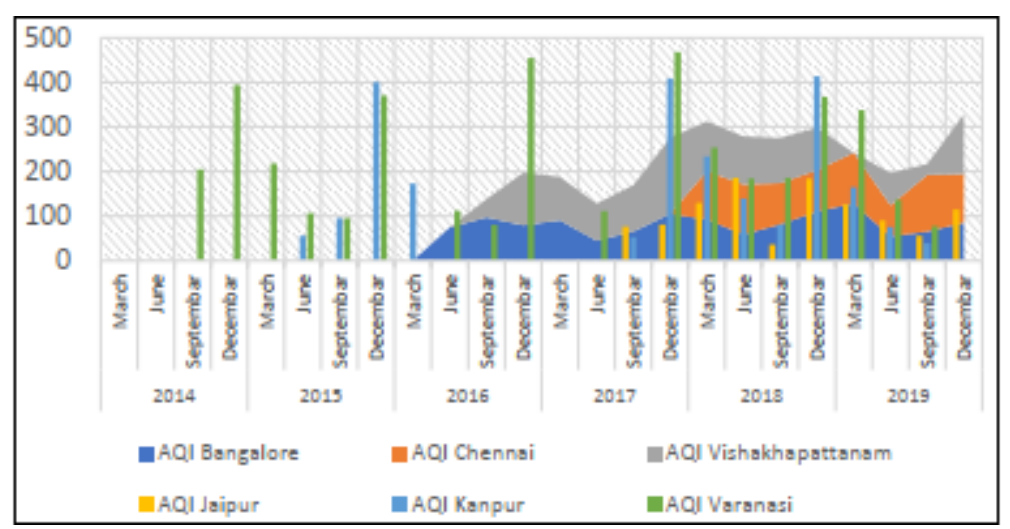

i) All Pollutants parameter of selected Cities:

All parameters of air pollutants are found that al cities Kanpur city are mostly pollutant city within all cities. Because Kanpur are most populous and industrial city in the state of Uttar Pradesh. Then Varanasi, Jaipur, Vishakhapatnam and Bangalore city another pollutant city within selected cities.

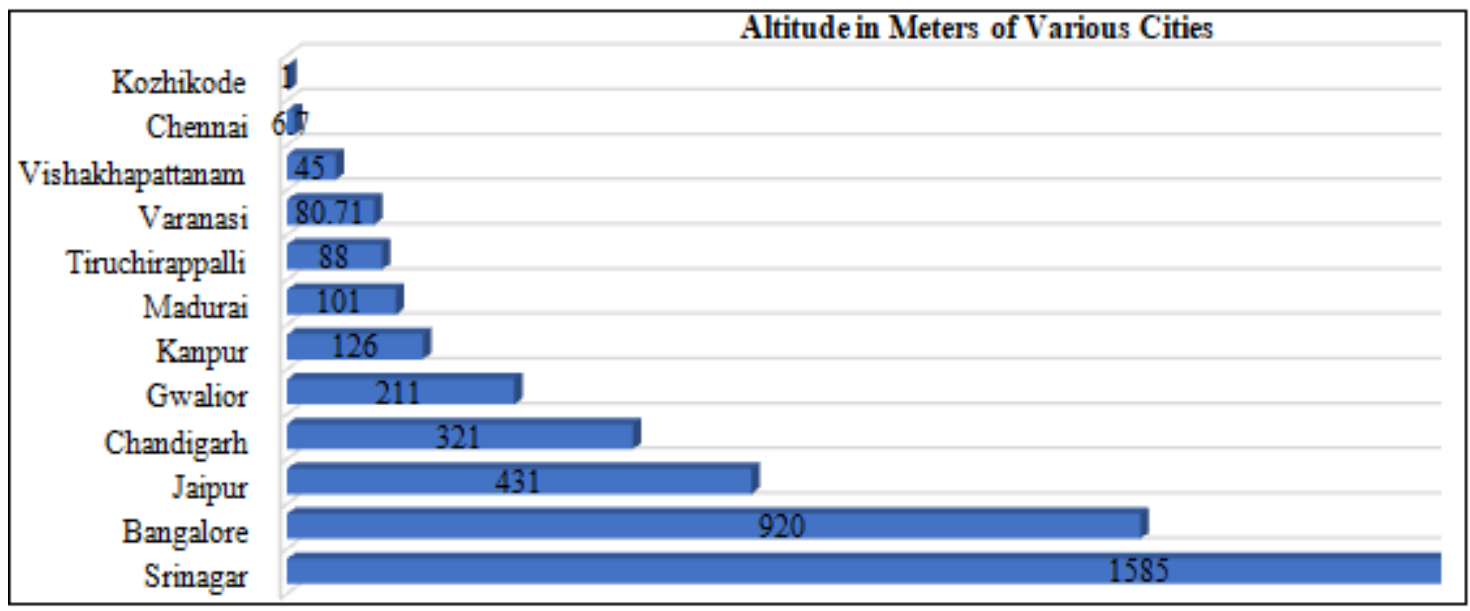

\section{Comparison between Urban population explosion rate and altitude of selected cities}

Here I found that Bangalore, Chennai, Vishakhapatnam, Jaipur and Kanpur are populous cities in these selected cities. Uncontrolled urbanization is rapidly destroying the standard atmosphere. Industrial activity is increasing day to day, that emission are important pollutants in the urban atmosphere. Here I selected approximation same populous city but differently their absolute location and altitude for my actual analytical argument on this paper.

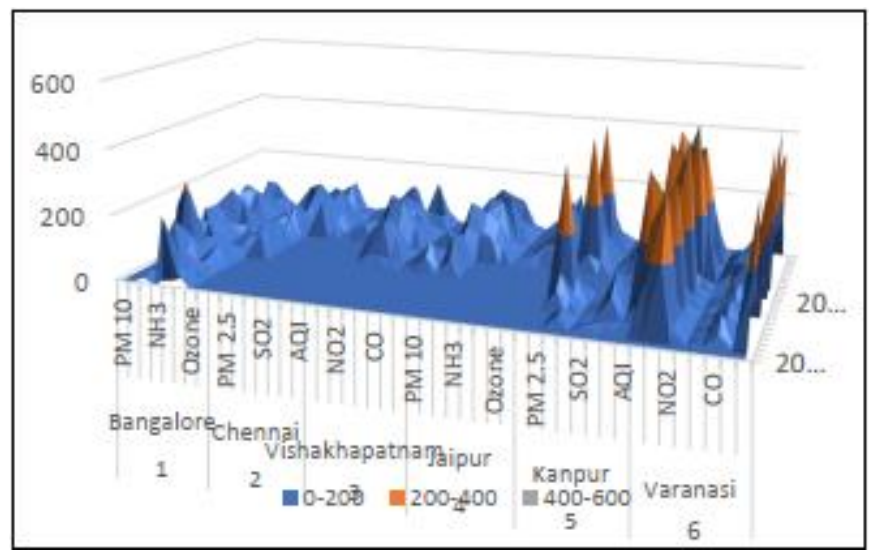




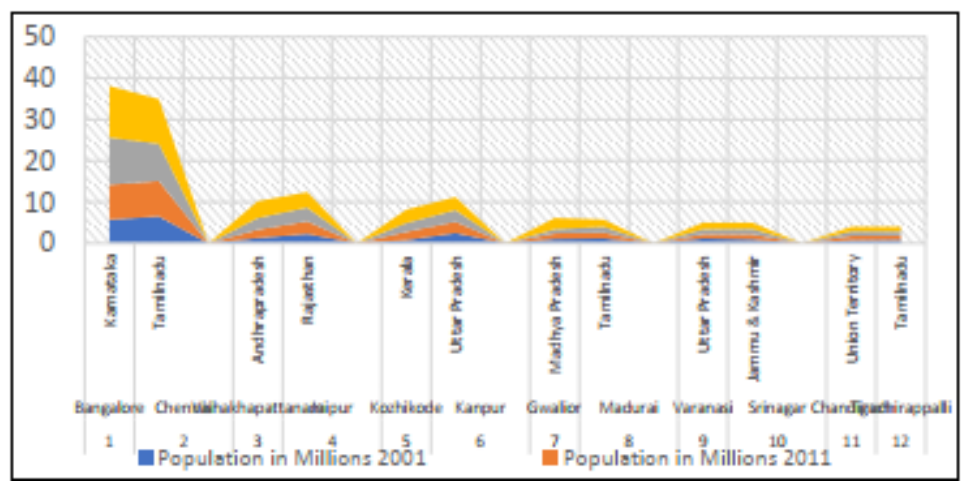

\section{Urban Growth map and Air pollutants growth rate level of various cities:}

Urban growth is a dynamic concept. Third world countries are rapidly urban growth. Urban growth is a best example of growth of sub-urbanization, urban sprawl and rurbanization within an urban surrounded region in India. Urban growth means a large amount of population explosion through identify their residential density, transport density etc. Here we assess the Landsat 8 series satellite image with the help of three bands for urban density growth identification during 2014-2018. Radiometric resolution is a best identification of reflectance density measures of every cities in this paper. Another assessment of air pollutant material assesses by the National Air Quality assessment official release data from central pollution control Board (CPCB). All air pollutants materials are determinants of urban microclimates and its microclimate determinants factors within the urban area.

\section{A) Bangalore and Chennai Metropolitan Cities:}

Both cities are selected on the basis of their number of metropolitan populations. Here we are found that metropolitan Population growth rate are approximately closer to each other. But their altitude and city microclimatic

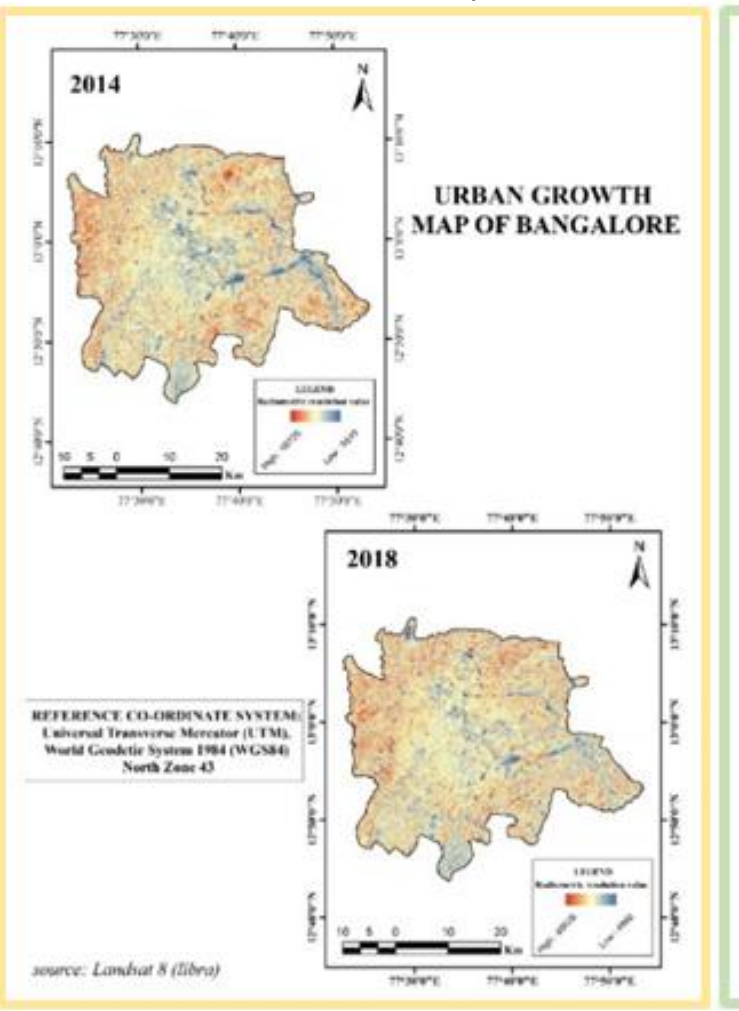

sensitivity are so different. We have seen that Air Quality Index are day to day increase of both cities by their explosion of population and industrial activity. But Chennai Air Quality Index (AQI) growth rate low than the Bangalore. Because Chennai Metropolitan city is achieved the more environmental sensitivity like rainfall, coastal storm than the Bangalore. The average annual rainfall of Chennai and Bangalore city are $1400 \mathrm{~mm}$ and $970 \mathrm{~mm}$. The altitude of Chennai and Bangalore cities are 6.7 meter and 920 meters. This city wettest months being August, September and October. Paediatrician Dr Yashoda Devi said, "Children Between two and eight years are most vulnerable during this season because of allergens in the air. This character is so important character in this city microclimate weather achieved due to absolute location, altitude and population explosions. Chennai city characteristics are coastal climatic type. Chennai metropolitan city air pollutants are clean up by the coastal storm, wind and rainfall. Another city Bangalore is much more achieve the interior plateau type climate. So, both cities absolute location and microclimatic condition is maintaining the pollutants level in their Air Quality Index. 


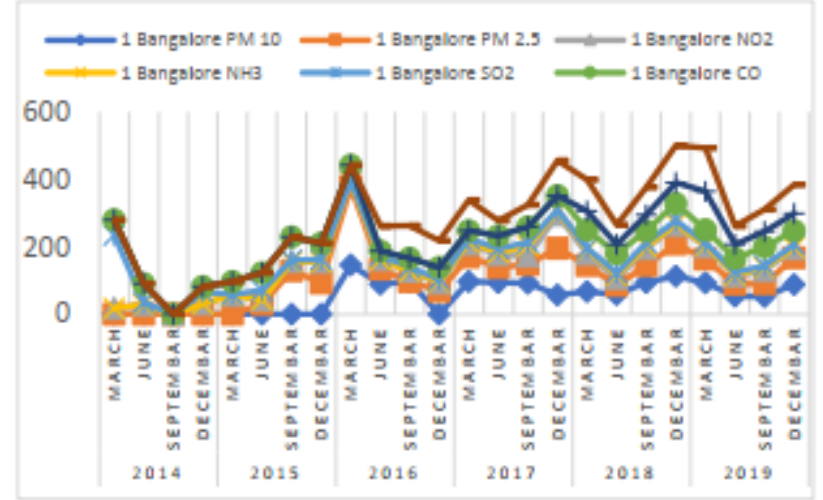

\section{B) Vishakhapatnam and Jaipur City:}

Vishakhapatnam city is a port type city. This city's altitude is 28 meters and this port city achieved the tropical wet and dry climate (Koppen Aw). Vishakhapatnam city Air Quality Index is very high than the Jaipur city. Because Vishakhapatnam city is known as the industrial city and Jaipur city is the state capital of Rajasthan. In both cities, we
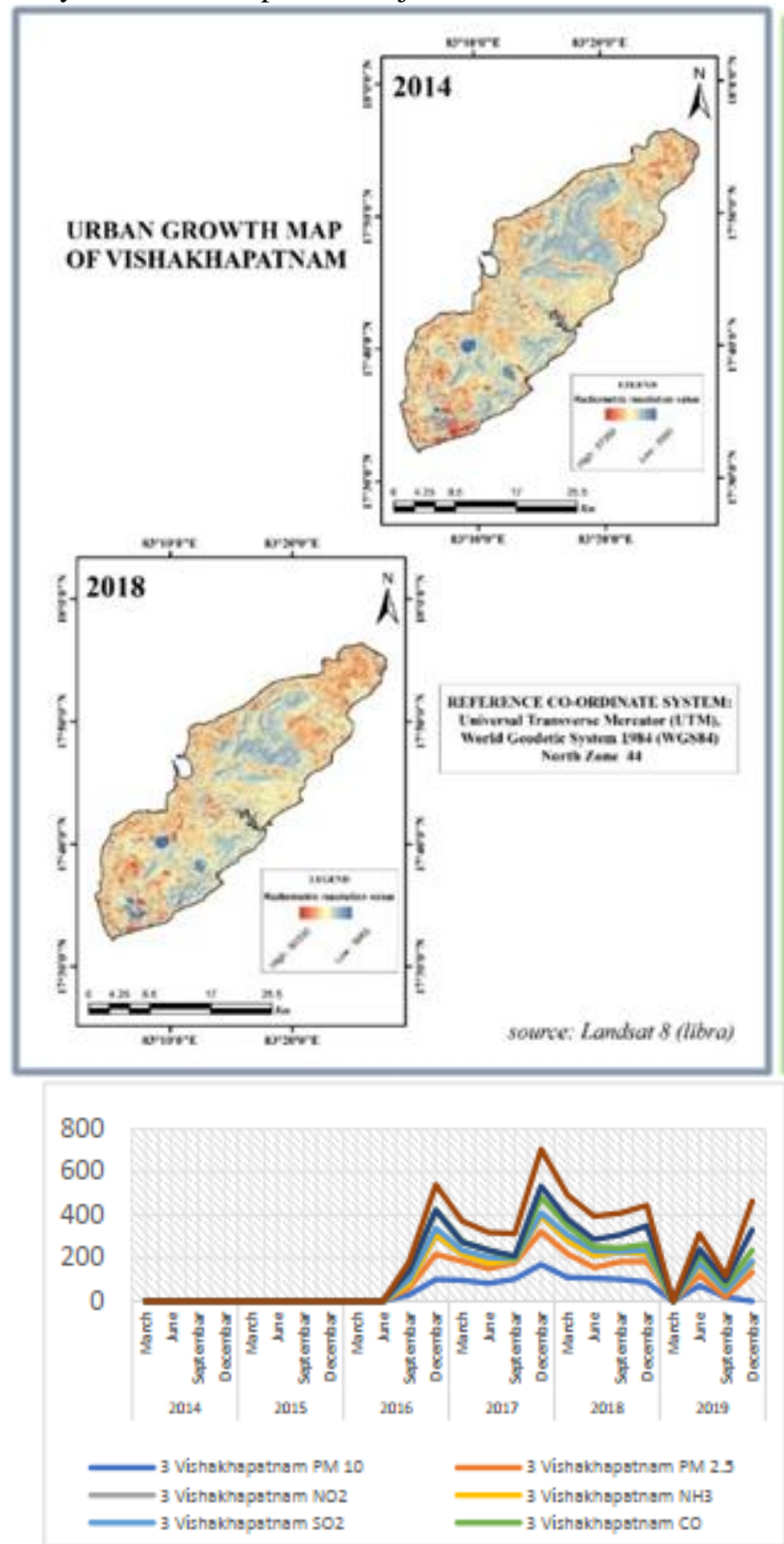

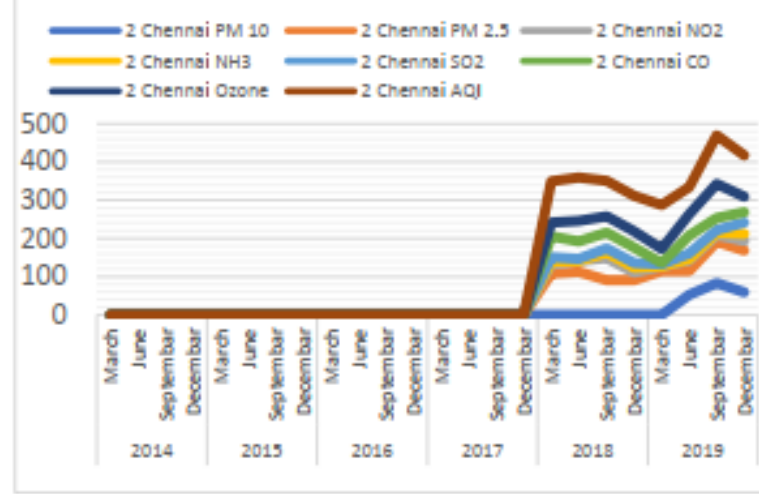

have found that closer population growth rate and the number of populations. Jaipur city microclimate is a continental type, and Jaipur city is more altitude than Vishakhapatnam. Vishakhapatnam and Jaipur city altitudes are 28 meters and 431 meters. And Vishakhapatnam city and Jaipur city annual rainfall is $1008 \mathrm{~mm}$ and $600 \mathrm{~mm}$.
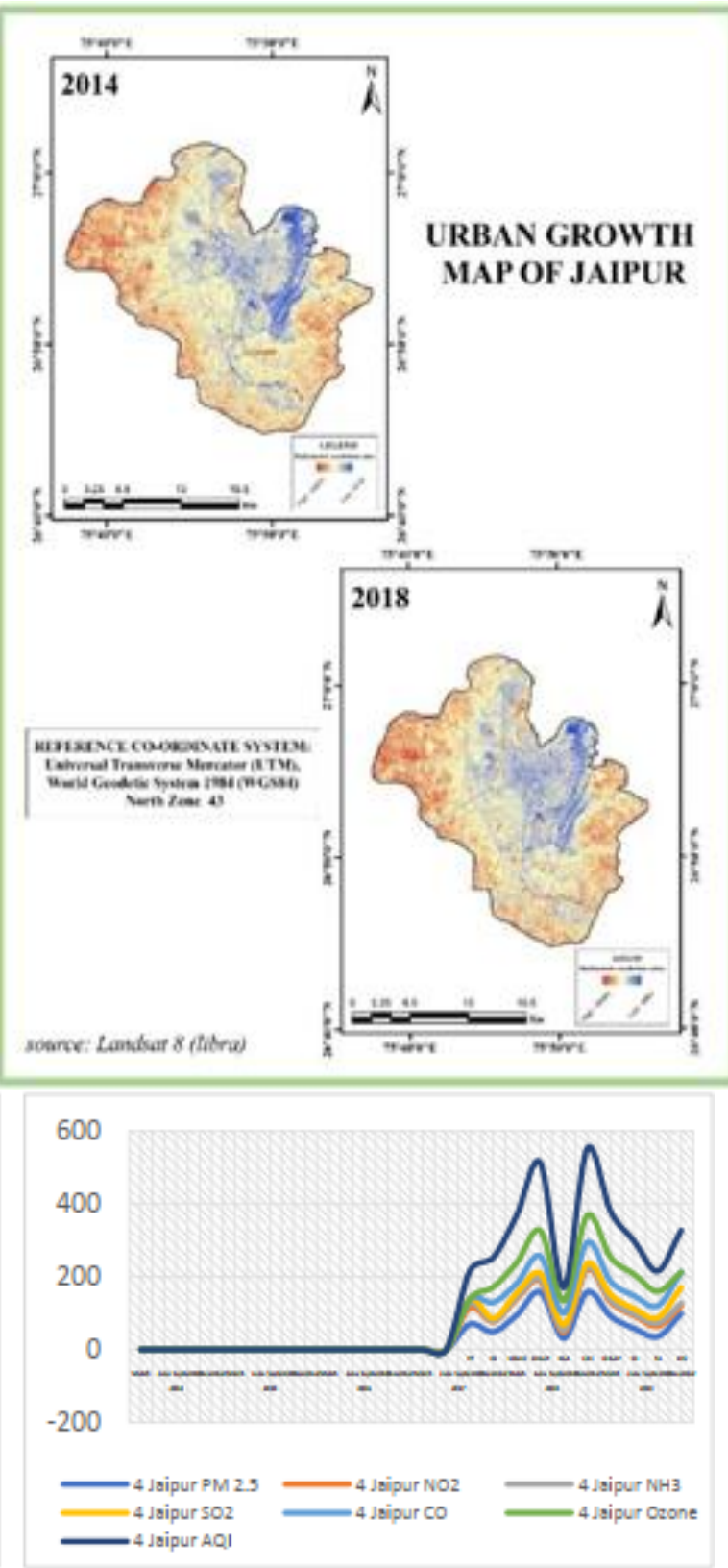


\section{C) Kanpur Metropolitan City and Kozhikode city}

Kanpur and Kozhikode city are located two different latitude and longitude in India. But basically, both populations are so different. We know that Kanpur Air Quality Index are so bad In the World. World top 10 polluted city list Kanpur metropolitan city are included this list. We are known that Kanpur city belong to dry-winter humid sub-tropical climate (Cwa) under the Koppen climate classification. Kanpur city are industrially and populous city in India. Kanpur
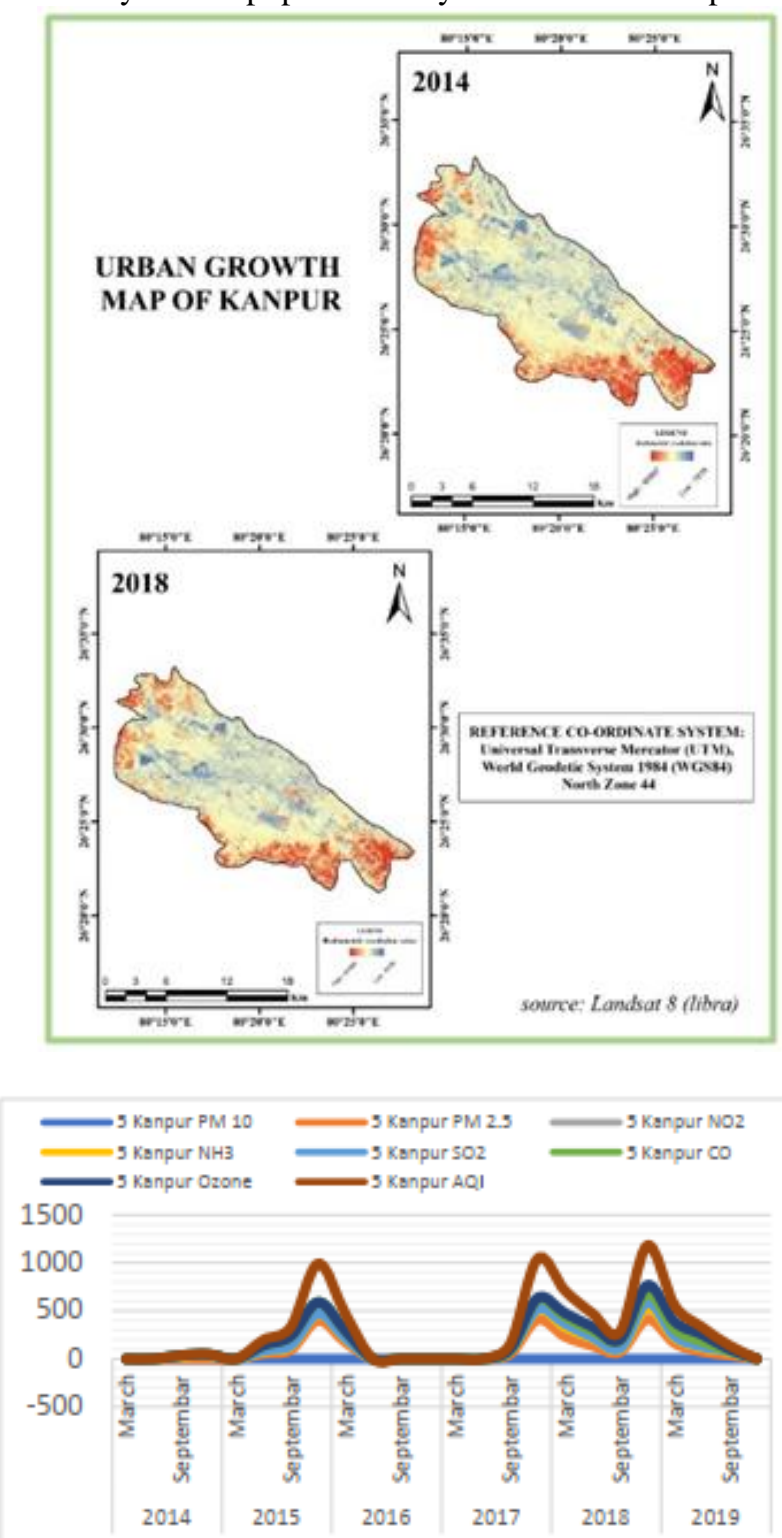

\section{D) Gwalior and Madurai City:}

Gwalior and Madurai city climate is so different from each other. Gwalior city and Madurai city microclimate are mild and tropical type. We have found that both city microclimate Csa and Aw in Koppen climate classification. Rainfall of both cities is $910 \mathrm{~mm}$ and $840 \mathrm{~mm}$ annually. Gwalior city and Madurai cities' average temperature is $25.7 \mathrm{C}$ and $28.8^{\circ} \mathrm{C}$ in their climate data recorded from Google sources. Gwalior metropolitan city and Kozhikode city altitude are 126m and 1 meter. We are known that Kozhikode city are achieved the coastal climate and Kanpur metropolitan city are achieved the interior sub-tropical climate in India. Kozhikode city AQI assessment from the January in 2020. We have found that AQI less than the Kanpur metropolitan city.
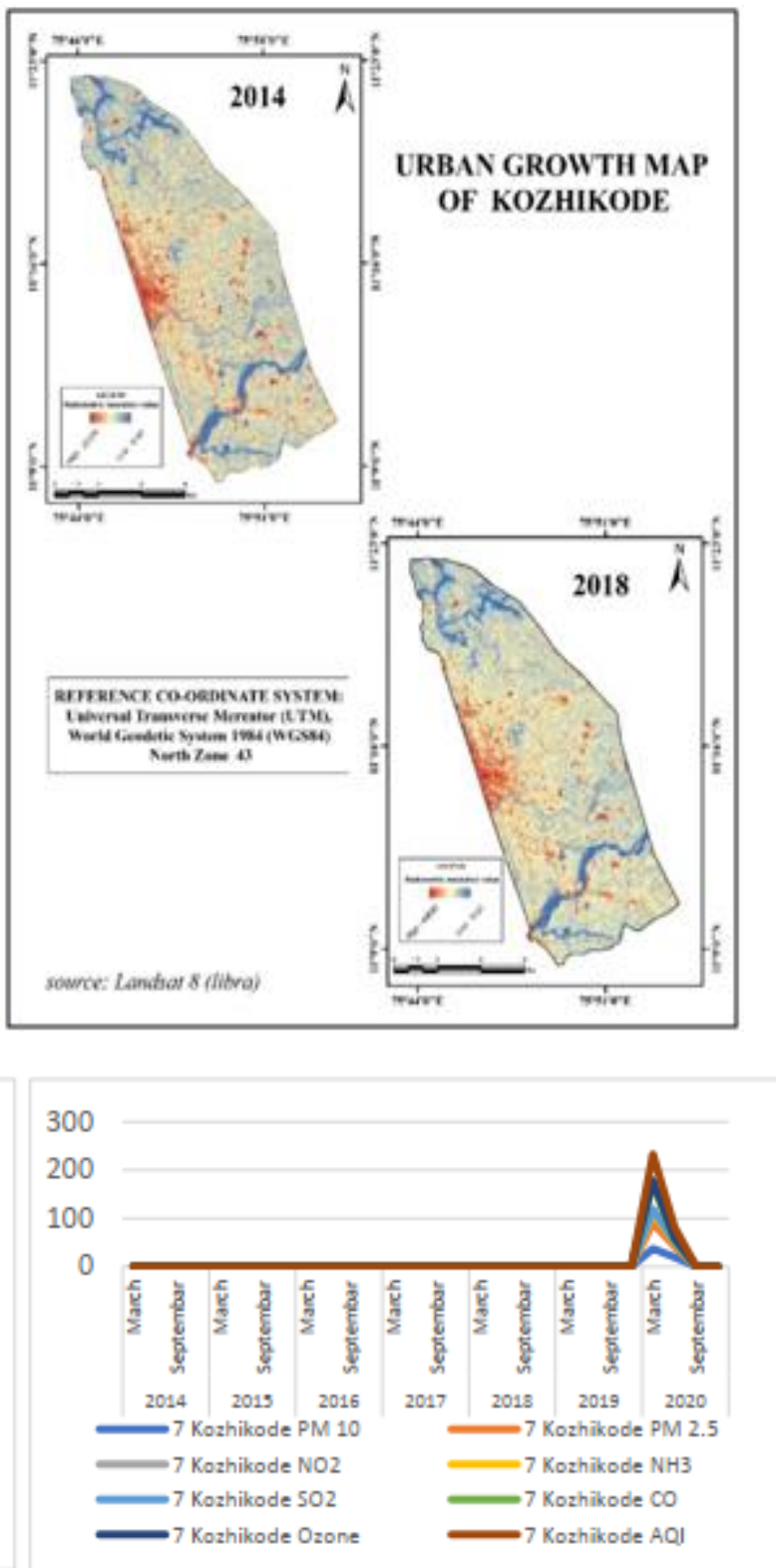

is metropolitan and Madurai city is the third-largest city in Tamilnadu state. Madurai city is the lowest pollutants than the Gwalior city. Madurai is an important industrial and educational hub in South Tamil Nadu. 

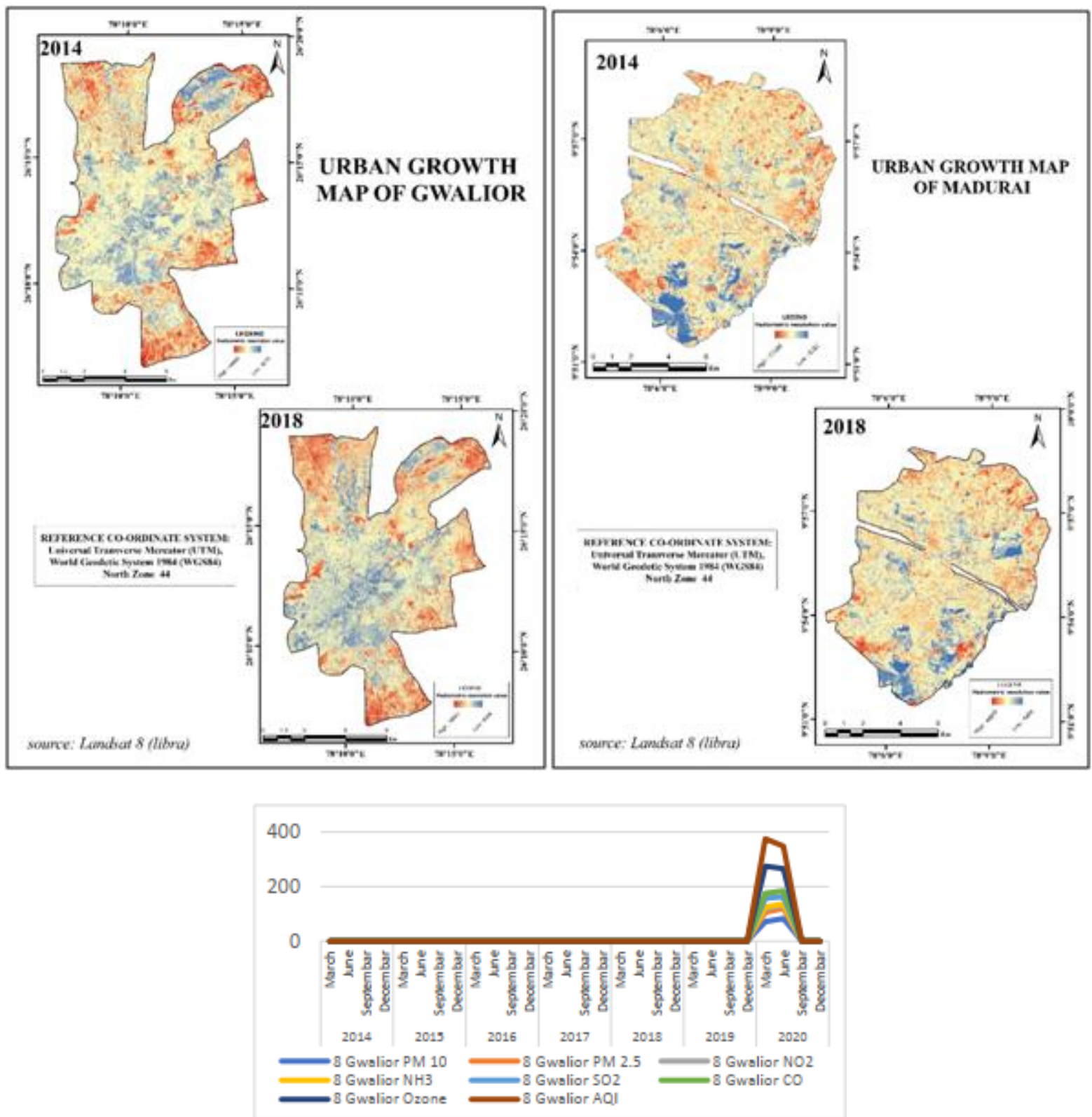

*Madurai City data not present in the National Air Quality in Central Pollution Control Board

\section{E) Varanasi and Srinagar City}

Varanasi and Srinagar both cities most populous cities in India. But altitudinally both cities located $76 \mathrm{~m}$ and $5400 \mathrm{~m}$ from mean sea level. Both cities climate is mild and generally warm and temperature. The rainfall in Varanasi mostly in the winter, with relatively little rain in the summer. But rainfall in Srinagar is significant, with precipitation even during the driest month. Varanasi and Srinagar city Csa and Cfa belong from Koppen and Geiger climate group. Varanasi and Srinagar average temperature in $26.1^{\circ} \mathrm{C}$ and $13.6^{\circ} \mathrm{C}$ annually. Rainfall is so different each other, Varanasi city $998 \mathrm{~mm}$ and Srinagar city 693mm annually found in both cities. We have known that Srinagar city are huge advantage from absolute location. Srinagar city are known to tourism and administrative city. Both cities are same population carrying but both city air pollutants level are so different by their natural environmental advantages. Natural environmental are very strong than the manmade environment for climatic pollutants level controlling in Srinagar City. Environmental sensitivity are huge responses in the 

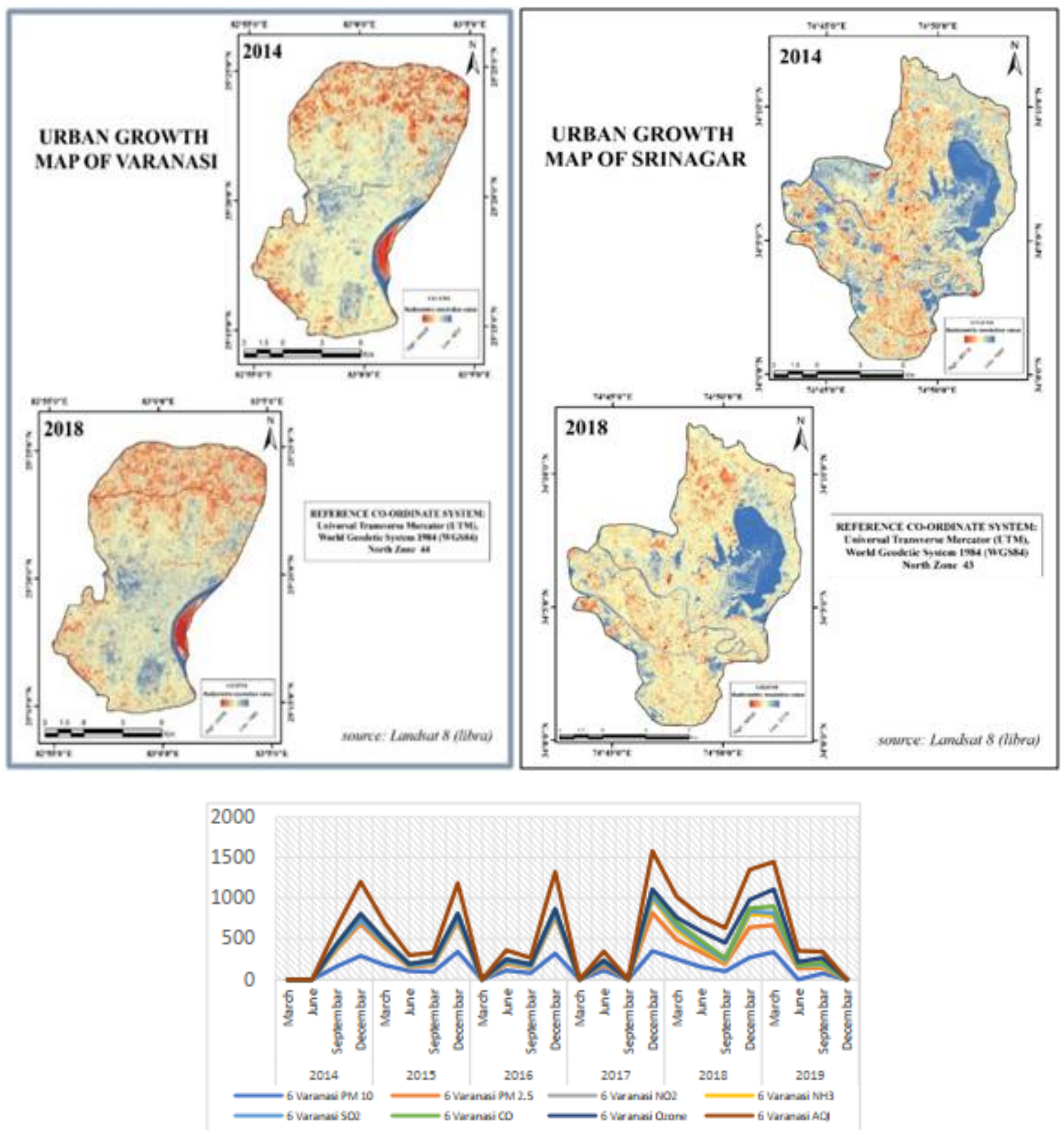

*Srinagar city than the Varanasi city. Varanasi city low laying city than the Srinagar city, and Varanasi city air quality is huge controlling by the social and cultural factors. So, Varanasi city huge pollutant city than the Srinagar city.

F) Chandigarh Capital city and Tiruchirappalli City:

Chandigarh city is one of the first radiant type planning city in India. Chandigarh is the capital city. Both city altitude is different each other Altitude are Chandigarh and Tiruchirappalli $337 \mathrm{~m}$ and $88 \mathrm{~m}$ from mean sea level. Chandigarh city climate is mild and generally warm temperate. Chandigarh city climate is Csa according to koppen and Geiger climate classification. and Tiruchirappalli experiences a dry-summer tropical savanna climate. Tiruchirappalli city climate is as type according to koppen climate classification. The average annual temperature of Chandigarh and Tiruchirappalli is $24.1^{\circ} \mathrm{C}$ and $28.9^{\circ} \mathrm{C}$. Average annual rainfall of Chandigarh and Tiruchirappalli is $979 \mathrm{~mm}$ and $841.9 \mathrm{~mm}$. 

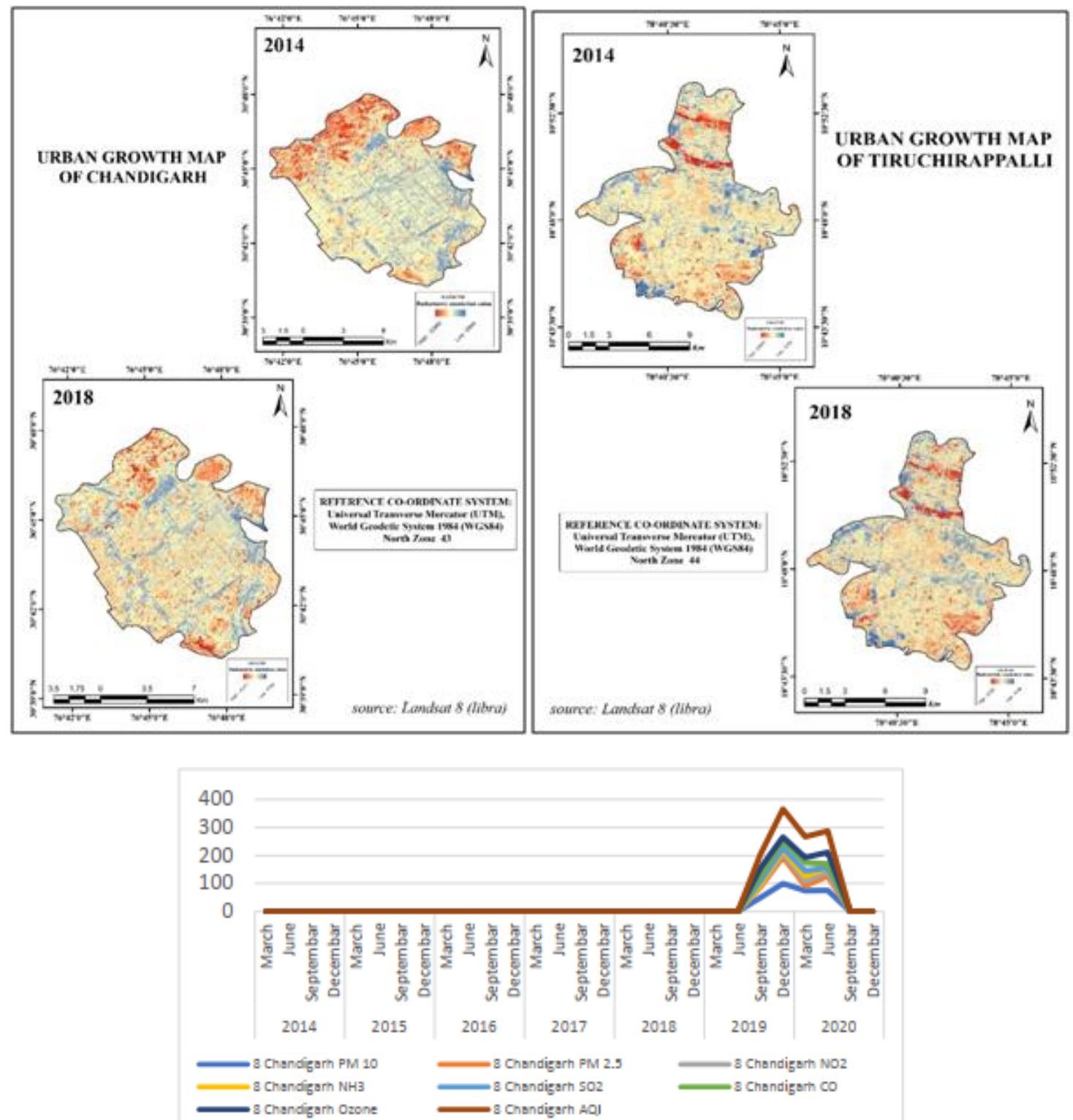

*Tiruchirappalli City data not present in the National Air Quality in Central Pollution Control Board

\section{G) Urban Map Different resolution value}

To see the all-urban map, analysis of Landsat 8 (libra.developmentseed.org) data also using the reference co-ordinate system: Universal Transverse Mercator (UTM), World Geodetic System 1984 (WGS84) North Zone 45.
Here I originally used the map of 2014 and 2018, which urban growth image created by three band (B2 - Blue, B5 Near Infrared, B7 - Shortwave Infrared 2) and the map was collected from libra.developmentseed.org. Table no.2:

\begin{tabular}{|c|c|c|c|c|c|c|c|c|c|c|}
\hline \multicolumn{11}{|c|}{ Different Urban maps related data } \\
\hline \multirow{3}{*}{ Town/City name } & \multirow{3}{*}{ Types of satellite image } & \multirow{2}{*}{\multicolumn{2}{|c|}{ Cloud coverage (\%) }} & \multirow{2}{*}{\multicolumn{2}{|c|}{ Sun Azimuth $\left({ }^{\circ}\right)$}} & \multicolumn{4}{|c|}{ Radiometric resolution value } & \multirow{3}{*}{$\begin{array}{c}\text { Study Area } \\
\text { (Sq. km) }\end{array}$} \\
\hline & & & & & & & & & 018 & \\
\hline & & 2014 & 2018 & 2014 & 2018 & Low & High & Low & High & \\
\hline Chennai & \multirow{12}{*}{$\begin{array}{c}\text { source: Landsat } 8 \\
\text { (libra.developmentseed.org) }\end{array}$} & 4.88 & 0.46 & 105.47 & 143.46 & 5509 & 50140 & 4953 & 54204 & 712.3329 \\
\hline Bangalore & & 0.04 & 0 & 106.76 & 128.12 & 5510 & 62725 & 4840 & 65536 & 1622 \\
\hline Kanpur & & 0 & 0 & 103.04 & 97.25 & 7278 & 50987 & 6935 & 65535 & 255.874 \\
\hline Jaipur & & 0.14 & 0 & 122.25 & 131.48 & 5733 & 54233 & 5861 & 54942 & 504.134 \\
\hline Vishakhapatnam & & 3.52 & 0.90 & 118.19 & 120.81 & 5380 & 57350 & 5665 & 65535 & 727.609 \\
\hline Kozhikode & & 3.92 & 0.22 & 143.94 & 144.54 & 5157 & 22379 & 5121 & 45680 & 224.343 \\
\hline Varanasi & & 0 & 0.70 & 94.72 & 114.43 & 6037 & 44449 & 7692 & 24978 & 197.254 \\
\hline Madurai & & 0.70 & 0.33 & 106.35 & 119.75 & 5222 & 61026 & 5499 & 48057 & 98.9129 \\
\hline Srinagar & & 5.35 & 0.56 & 149.53 & 155.70 & 5067 & 46715 & 5178 & 65535 & 188.944 \\
\hline Gwalior & & 0 & 0.02 & 118.20 & 101.75 & 6274 & 48888 & 8484 & 30851 & 212.477 \\
\hline Chandigarh & & 0.01 & 0.79 & 105.65 & 103.39 & 6844 & 32883 & 6788 & 35253 & 119.17 \\
\hline Tiruchirappalli & & 0.02 & 0 & 109.06 & 121.84 & 5216 & 37803 & 5409 & 27591 & 142.17 \\
\hline
\end{tabular}




\section{Major Findings}

We have known that in urban air quality always dependent on urban ecology. Urban ecology has been used variously to describe the study of humans in cities, and its nature in cities. Basically, it means coupled relationships between humans and nature. Each of these research areas is contributing and each must be understood to fully grasp the science of Urban ecology in Urban sciences. Here we have found that important subject of this paper is;

1) Particulate matters 10 and 2.5 sizes are more found that interior plainland cities in India. Particulate matter 2.5 and 10 sizes present Varanasi and Kanpur cities microclimate more than the other cities, because both are interior plain cities. We have known that all type particulate matter is wash out by the strong wind and rainfall. But these metropolitan cities less atmospheric wind energy and moisture present in their microclimate for purified these polluted materials.

2) Another Coastal metropolitan city's like Chennai, Vishakhapatnam lowest particulate matter present in their microclimate. These are polluted materials are wash out by the strong wind and cyclonic storm. So basically, these metropolitan cities AQI are lowest than the interior cities.

3) Another air pollutants $\mathrm{NO}_{2}, \mathrm{NH}_{3}$ and $\mathrm{SO}_{2}$ are more found that Varanasi, Kanpur and Jaipur cities in their microclimate due to lack of strong climatic agents for purified the cities microclimate. But Chennai, Vishakhapatnam and Bangalore cities lowest these pollutants materials than the other cities due to more atmospheric agent's activity found that in these regions.

4) When we have seen that all over the Air quality Index of selected cities, we have found that Jaipur, Bangalore, Chennai and Vishakhapatnam are less AQI carrying sequentially than the Varanasi and Kanpur cities. Because their different urban ecology and their microclimatic significance.

5) Climatic hazards always wash out the polluted materials from the microclimate in these urban areas. Cyclone and flash flood are always very strong effect on Vishakhapatnam, Chennai, Kozhikode, Srinagar cities in India. AQI index drop these cities by these strong microclimatic agents and their activity.

6) These metropolitan cities growth and increases their air pollutants, that's are mainly a general urban pollutants concept in India. But natural microclimatic factors are prominent factors for controlling the air quality in these selected urban areas.

All measurements results are express to urban air pollutants status change detection of selected cities. Two hypotheses are built up on these measurements, and which is the prominent factors for build-up the microclimate in these selected cities. Some cities microclimate builds by microclimatic more sensitivity agents like rainfall, storm and cyclonic activity.

\section{Suggestion}

In spite of all urban areas government should come out first in clear terms in favour of a strict National urbanisation policy, which is closely linked with urban population and int environmental pollution. Here interior cities are mainly polluted due to anthological activity. Varanasi, Kanpur, Gwalior and Bangalore cities are found more polluted than the other cities. Because we know that environment are selfregulated and purified extremes their pollutants materials in urban climate. Other cities are strong environmental activity and purified extreme pollutants from their microclimate in selected cities. Important urban suggestions are controlling of urban pressure and purified of air pollutants material from urban region. Important suggestion is given bellows;

1) Avoid the congestion and allied problems in metropolitan area by the use of decentralisation policy and promotion of small towns in India.

2) Intensive study of all type urban problems and relation with urban settlements patterns and growth. An institutional framework for the management of urban affairs in all type problematic cities in India.

3) Our always realize the western urbanisation philosophy concept and that it believed in Indian urbanisation. i.. e.., Industrialization urbanisation Modernisation, it is not the best path of us. The growth of urbanisation of our countries are developed in the way of Cultural centres Administrative centres Economic centres.

4) The ecological hazards in urban area are directly proportionate to this overcrowding. So basically, small scale and medium scale industry shifted from urban centre or overcrowding centre area to backword or side word village. And some important offices or institution build-up from overcrowding area to dispersed type build-up in urban region.

5) Rural development programme is the broad spectrum of decentralized planning and control the emigration from rural region in India.

6) Slum area we are known this is a always carrying huge population and excessive polluted region within any urban region in India. So, slum improvements and clearance are a big part of urban planning and policy in India.

7) The growth of small towns should be encouraged to metropolitan migrants and providing them sufficient economic and social infrastructures.

8) Increase the air quality awareness and digital alarming system within the urban area for regulate the air pollutants materials.

9) Environmental taxation or green taxation policy apply for city healthy microclimate build-up within the cities in India.

10) Increase the open space and park centres within the city for heat releases and wind movement activity are increases. Less concretization of open space, park, garden and footpath for better infiltration of rain water and fill-up the ground water.

Every urban area in India are faces huge problem lack of their uncontrolled urbanization and lack of proper management. Environmental determinism and anthropological determinism both are tremendously impact on urban microclimate build-up in these urban areas. A good urban planner always build-up a good plan on the basis of urban input, processing and output. Because urban ecology always builds by the environment and manmade activity in these selected cities. All million-urban area in India found the uncontrolled urbanization and rapidly change their Air 
pollutants level. Here all selected cities are decrease their vegetation cover due to population explosion in these urban areas. I have suggested that all urban corporation or Urban governance are accepted the 'Green City' policy and taking action for developed their vegetation cover within the city. Solid waste management are another important factor for healthy urban environment build-up. Because solid waste is not to proper management in India due to lack of environmental awareness. When our increase the percentage of vegetation cover within the cities, then the cities air pollutants are controlled. Because vegetation is the good consumer of all type of air pollutants.

\section{Conclusion}

Air pollution remains a leading environmental concern of urban region in India. Continuous air pollutants level monitoring is the best way to known and alert the air quality of urban area in India. Every atmospheric hazardous are best way to controlling and modified to microclimatic pollutants purified the urban microclimate. Such as rainfall, flash flood and storm wind are always best way to purified the urban air quality. Above these hypotheses are express on environmental sensitivity level measure of differently located urban region in India. Because we have found that Coastal cities and plateau cities always less polluted than the plain land cities. Best example of Bangalore is an industrial metropolitan city, and Kanpur and Varanasi metropolitan less industrial activity base cities. But Bangalore are less polluted than the Kanpur and Varanasi metropolitan area. Such as Jamshedpur is a big industrial plateau city, this city's atmospheric pollutants level is less than the Kanpur and Varanasi cities. So, cities space and ecology are prominent factors for AQI build-up in their urban area than the anthropogenic activity. We have found that coastal cities and mountainous or plateau cities less polluted than the plain land cities.

We know that urban growth and air pollutants level increases it is the general matter in urban geography. Microclimate in the Urban area are dependable on-air temperature, humidity, wind and air pollutants, this are created by the natural phenomena like city absolute location, sun inclination and altitude, but other phenomena of anthropogenic activity are another prominent factor for urban microclimate build-up in urban region. Urban morphology is called an environment that are produce by the human activity.

We found that approximate same number of populations between two cities are different their atmospheric pollutants. Like Srinagar and Varanasi are approximation same number of population but Srinagar are good air quality better than the Varanasi city. Because Srinagar absolute location, sun inclination angle and altitude are more energetic for remove and recover the air quality better than low altitudinal and more sun insolation Varanasi city. Another example of Vishakhapatnam and Jaipur city. Vishakhapatnam and Jaipur city are approximate same population carry but Vishakhapatnam city air found are more air pollutants than the Jaipur city. Bangalore and Chennai are millions plus city in the world. Bangalore important IT city in India. Huge Industrial activity found in the Chennai metropolitan cities.
But Bangalore Air Quality Index are better than Chennai city, because Bangalore are situated high altitude and these cities are achieved different climate due to absolute location and absolute location. We know that standard atmosphere is depend on two perspective, first of one Environmental Determinism and second is Anthropogenic Determinism.

That means population increase does not matter for degradation Urban microclimate in the earth. Important matter is which are more control the urban microclimate, when Environmental energy are more control the urban atmosphere then the urban atmosphere air pollutants are control and build-up the standard atmosphere in the Urban microclimate. When Anthropogenic activity are more energetic than the Environmental energy then the city microclimate is day to day polluted within the city. Atmospheric disturbance, like rainfall, strong wind and snow fall are much more found any city, this city air pollutants lowest another city. Here Kozhikode and Kanpur city are approximate same population carry, but Kanpur is the high polluted cities in India. But Kozhikode city are low polluted because this city is gain huge rainfall due to South west Monsoonal rainfall. So, urban expansion due to rapidly population increasing does not matter for air pollutants increase within the Urban microclimate. The study also is found a significant correlation between Increasing the population, comparison air pollutants of different cities with different time wise analysis within the selected cities in India.

\section{Further Research Gap}

Research gap is another important way towards selected research area and topics. Here research gap of my study area is assessing the percentage of vegetation cover and count the natural calamity within the city for actual measurement the environmental sensitivity in this Urban area. Because natural energy like precipitation is more heat which cities, these cities are more pollution free then the lowest natural heat cities. Like Srinagar, Kozhikode, Jaipur and Bangalore city gain the more precipitation than the other selected cities. Effect Srinagar, Kozhikode, Jaipur and Bangalore cities are less pollutants present in their air.

\section{Limitation of the study area}

Limited of this study area are, not to assess the selected cities air pollutants level. Because lack of Air Quality Monitoring station all selected cities. Here Srinagar, Kozhikode city no Air Pollutants data available. Due to cloud coverage are another obstacle of proper access to Build-up density of selected cities. Population census are another limitation of this paper, because census is occurred 10-year interval. Here I have searched the google, and collected the number population on selected cities then analysis on 2001, 2011, 2014 and 2018 years total population. I don't have known to proper microclimate on selected cities, I just analysis the Air Pollutants level and build-up hypothesis for this paper. 


\section{Acknowledgement}

I would like to express my deep gratitude to Professor Nilanjana Das Chatterjee and Srikrishna Paul for their patient guidance, enthusiastic encouragement and useful critiques of this research work. I would also like to thank Dr.Abhisek Chakrabarty for her advice and assistance in keeping my progress on schedule. My grateful thanks are also extended to Mr. Souvik Mondal for his help in doing the urban growth map analysis by the uses of Landsat 8 series images. I would also like to thank my college and departmental staff for their help in offering me the resources in running the programme.

Finally, I wish to thank my parents for their support and encouragement throughout my study.

\section{References}

[1] Amirtham L.R. Urbanization and its impact on Urban Heat Island Intensity in Chennai Metropolitan area, India, Indian Journal of Science and Technology, Vol 9 (5), DOI: 1017485/ijst/2016/v915/87201, February 2016.

[2] Amirtham R.L, Horrison. E. Rajkumar.S, Impact of urban morphology on Microclimatic conditions and outdoor thermal comfort- A case study in mixed residential neighbourhood of Chennai, India, ICUC9 9th International Conference on Urban Climate jointly with 12th Symposium on the Urban Environment, 15 June 2015.

[3] TTri. SD, Tyagi.A, climate profile of India, contribution to the Indian networkof climate change assessment (National Communication-II) New Delhi; Government of India; 2010.

[4] Banerjee S, Sen.R, Chattopadhyay. S, A comparative study on the effects of urban morphology on the Urban heat island profile in ResidentialNeighbourhoods: A case of Kolkata, India, t: https://www.researchgate.net/publication/323072157

[5] Beermann J, Damodaran.A, Jorgensen.K, Climate action in Indian Cities: an emerging new research area, journal of Integrative Environmental Sciences, Pages 55-66, 17 January 2016, https://doi.org/10.1080/1943815X.2015.1130723

[6] Chaturvedi A, Kamble R, Patil NG, Chaturvedi A. Cityforest relationship in Nagpur: One of the greenest cities of India. Urban Forestry \& Urban Greenery. 2013;12:79-87. Doi:10.1016/j.ufug.2012.09.003

[7] Devdas, M.D., and lilly Rose A. 2009. Urban factors and the intensity of heat island in the city of Chennai. In the seventh international conference on urban climate. Yokohama, Japan

[8] Greater Vishakhapatnam Municipal Corporation (GVMC) 2015, GVMC Horticulture. Retrieved May 18, 2015 , from https://www.gvmc.gov.in/gvmc/index.php/menustyles/horticulture.

[9] Gulia S, Khanna I, Urban air quality management-A review, Atmospheric pollution Research, Volume 6, Issue 2, March 2015, Pages 286-304, https://doi.org/10.5094/APR.2015.033
[10] Khosla. R, Bhardwaj. A, Urbanization in the time of climate change: Examining the response of Indian cities, Willey Analytical Science, 26 November 2018, https://doi.org/10.1002/wcc.560

[11] Mohanraj R, Azeez bP.A, Urban development and particulate air pollution in Coimbatore city, India, Pages 69-78, 1 Feb 2010, International Journal of Environmental studies, https://doi.org/10.1080/0020723042000261713

[12] Nasir Humaib, Goyal Kriti, Prabhakar Dolonchapa Review of Air Quality Monitoring: Case study of India, Indian Journal of Science and Technology, Vol 9 (44), DOI: $\quad 10.17485 / \mathrm{ijst} / 2016 / \mathrm{v} 9 \mathrm{i} 44 / 105255$, November 2016

[13]R. Rajamanickam, Nagan, Assessment of Air Quality Index for Cities and major Towns in Tamilnadu, India, Journal of Civil \& Environmental Engineering, vol 8 (2):304, 2018

[14] Saravankumar.R, Sivalungam. S, Elangovan. S, Assessment of Air Quality Index of Coimbatore City in Tamil Nadu, Indian Journal odSSCience and Technology, $\quad$ vol 9 (41), $\quad$ DOI: 10.17485/ijst/2016/v9i41/99185, November 2016

[15] Thomas. G, A.P. Sherin, Zachaeiah. J.E, Analysis of urban heat island in kochi, India, using a modified local climate zone classification, Urban Environmental Pollution 2013- creating Healthy, Liveable Cities

[16] Sarella. G, Khambete. K.A, Ambient Air Quality Analysis using Air Quality Index-A case Study of Vapi, IJIRST -International Journal for Innovative Research in Science \& Technology| Volume 1 | Issue 10 | March 2015

[17] Mahalingam. B, M.Vinay. Ramu, A comparative temperature study of south India metropolitan cities in India using remote sensing and GIS technique, International Journal of Engineering Technology and Computer Research (IJETCR) Available Online at www.ijetcr.org Volume 2 Issue 5 Page No. 27-39

[18]Li. X, Mitra. C, Dong. L, Yang. Q, Understanding land use change impacts on microclimate using Weather Research and Forecasting (WRF) model, Physics and Chemistry of the Earth $\mathrm{xxx}$ (2017)1-12, www.elsevier.com/locate/pce 